\title{
Trabalho docente com jovens e adultos nas perspectivas dialógicas de Paulo Freire e Mikhail Bakhtin
}

\author{
Marcia Soares de Alvarenga ${ }^{1}$
}

Marcela Parmanhane Garcia ${ }^{2}$

Resumo: A pesquisa realizada junto às professoras alfabetizadoras de jovens e adultos nos mobilizou a compreender como os enunciados orais e escritos dos estudantes poderiam contribuir para transpor dificuldades em relação ensino da língua materna em turmas de alfabetização inicial e continuada de jovens e adultos. Orientada pela perspectiva dialógica de Paulo Freire e Bakhtin, a questão sobre como as professoras iriam dispor de acervos enunciativos evidenciou o desafio epistemológico relacionado à ideia de que se fariam sentidos, para as próprias docentes, os textos produzidos pelos alunos nos contextos das aulas. Os resultados da pesquisa ressaltaram dois relevantes aspectos: se, por um lado, a preocupação das professoras com a correção linguística se manteve como objetivo principal do ensino da língua materna, por outro lado os enunciados dos estudantes foram reconhecidos como textos, objetos de sentido para a alfabetização, favorecendo o encontro de várias consciências, de vários textos.

Palavras-chave: Trabalho docente. Alfabetização de jovens e adultos. Dialogismo.

Muito embora o Brasil tenha ampliado positivamente os indicadores sociais e educacionais nos últimos cinco anos (PNAD, 2008), os índices de analfabetismo entre pessoas com mais de 15 anos continuam a confrontar políticas públicas e, também, as escolas e seus educadores que têm, na Educação de Jovens e Adultos (EJA), uma das modalidades de escolarização.

Ao nos defrontar diante das difíceis barreiras histórico-sociais enfrentadas pelos estudantes da EJA, vemos que o professor de jovens e adultos é desafiado a produzir sentidos sobre saberes/práticas/experiências no/do exercício da docência, a elaborar a crítica sobre os dilemas da escolarização precária destes sujeitos e a afirmar que estes jovens e adultos não escolarizados e não alfabetizados são sujeitos de direitos, conhecimento e aprendizagens.

A complexidade que envolve estes movimentos de sentidos ${ }^{3}$ no faz reconhecer que é grande o desafio de aproximar Bakhtin e Paulo Freire, dois pensadores que nos legaram a

\footnotetext{
1 Professora da Graduação e do Mestrado em Educação Processos Formativos e Desigualdades Sociais da Faculdade de Formação de Professores da Universidade do Estado do Rio de Janeiro. Pesquisa financiada com auxílio FAPERJ. E-mail: msalvarenga@uol.com.br.

${ }^{2}$ Graduada em Letras e Mestranda do Programa Processos Formativos e Desigualdades Sociais da Faculdade de Formação de Professores da UERJ. Bolsista CAPES. E-mail: parmanhane_marcela@yahoo.com.br.

${ }^{3} \mathrm{Na}$ primeira seção deste artigo abordaremos esta noção referenciada em Bakhtin (2000).
} 
perspectiva dialética e dialógica da linguagem nas Ciências Humanas. Relembramos, aqui, o belo trabalho de Geraldi (2005) como um dos primeiros a promover este encontro, ou melhor, e em suas palavras, um encontro que não houve, em face às condições em que viveu cada um destes autores em seus respectivos contextos históricos, sociais e políticos.

No entanto, podemos dizer que seus trabalhos se entrelaçam, dialogam, fazem sentido para educadores e educadoras que buscam construir uma "pedagogia da autonomia" (FREIRE, 2011), em que docência e discência, enquanto relação, são indissociáveis, interrogam e são interrogadas pelas condições materiais de vida e de trabalho dos sujeitos que participam desta relação.

No presente artigo, esclarecemos que o problema da pesquisa foi inicialmente construído através de trabalho em que inter-relacionamos pesquisa ${ }^{4}$ e extensão, realizado entre a Faculdade de Formação de Professores/UERJ (FFP/UERJ) e uma escola pública de periferia urbana no município de São Gonçalo, localizado no leste metropolitano do estado do Rio de Janeiro.

Inicialmente nosso principal objetivo era analisar os sentidos atribuídos pelas professoras à sua formação, ou seja, como respondiam sobre as dificuldades e potencialidades de serem professoras de jovens e adultos. No curso de nossa inserção no campo empírico da pesquisa, a questão da alfabetização tornou-se, também, uma questão relevante, pois vimos estar, inequivocamente, vinculada ao problema da formação de professores, considerando que as três professoras participantes da pesquisa atuavam com turmas de alfabetização (Grupo I ${ }^{5}$ ) e pós-alfabetização (Grupo II).

Tendo como perspectiva a linguagem em sua dimensão dialética e dialógica, o presente artigo é fruto de um dos objetivos da pesquisa que buscou analisar que sentidos fazem para as professoras alfabetizadoras os textos orais e escritos por estudantes jovens e adultos em contexto de aula?

O artigo foi organizado em três seções. Na primeira seção, discorremos brevemente sobre a perspectiva dialética dialógica da linguagem, aproximando Paulo Freire e Mikhail Bakhtin; na segunda seção, abordamos o percurso teórico-metodológico, o problema e questões da pesquisa ancoradas em noções e conceitos dos dois autores centrais deste artigo;

\footnotetext{
${ }^{4}$ Trata-se da pesquisa Produção de sentidos sobre políticas de formação de professores de jovens e adultos, em que buscamos analisar sobre que sentidos os professores de jovens e adultos atribuíam à sua formação docente. A pesquisa contou com apoio FAPERJ para o período 2010-2011.

5 A Educação de Jovens e Adultos na cidade de São Gonçalo é organizada em três grupos: Grupo I Alfabetização; Grupo II - que corresponde a $3^{\circ}$ e $4^{\circ}$ ano do Ensino Fundamental 1 (EF); Grupo III $-5^{\circ}$ e $6^{\circ}$ ano do EF; e Grupo IV - que corresponde ao $7^{\circ}$ e $8^{\circ}$ ano de escolarização do EF.
} 


\section{$\begin{array}{llllllll}\mathbf{R} & \mathbf{E} & \mathbf{V} & \mathbf{I} & \mathbf{S} & \mathbf{T} & \mathbf{A} & \text { N. } 24-2012.2-\text { MARCIA S. DE ALVARENGA }\end{array}$ \\ MARCELA P.. GARCIA}

já na terceira seção, dialogamos sobre excertos orais e escritos de estudantes jovens e adultos em contexto de sala de aula, entrelaçando possíveis sentidos produzidos por professoras alfabetizadoras, ao cotejarem textos dos estudantes. Nas (in) conclusões, mantemos perspectivas abertas para a continuidade de outros possíveis sentidos ao trabalho de pesquisa, considerando dados que ainda dispomos para novos desdobramentos e que compõem o corpus empírico da pesquisa.

\section{Notas sobre a perspectiva dialética e dialógica da linguagem em Paulo Freire e Mikhail Bakhtin}

Realizar o duplo movimento da pesquisa e da docência em diálogo com os saberes de jovens e adultos potencializa a compreensão responsiva sobre a questão-convite feita por Freire (1996, p. 30): "Por que não estabelecer uma 'intimidade' entre os saberes curriculares fundamentais aos alunos e a experiência social que eles já têm como indivíduos?”.

No mundo da escola da EJA, no seu tempo miúdo (MARTINS, 2005), jovens, homens e mulheres adultos buscam realizar conquistas fundamentais: o direito à educação que lhes fora negado, o direito a ler e escrever, a ter uma "vida melhor". A escola como um local no qual, como inspira Santos (1994), o exercício de estudar o que nele existe de singular, de específico, de diferente nos permite refletir e refratar possibilidades de produção dos inéditos viáveis, como nos ensina Freire (1996, p. 30) em sua abordagem político-epistemológica sobre a educação e a prática educativa.

Como dissemos, a escola na qual vimos realizando a pesquisa, pertence à rede pública municipal de São Gonçalo, município do leste metropolitano do estado do Rio de Janeiro, cujo índice de analfabetismo, entre pessoas com mais de 15 anos, aproxima-se a $6 \%$, um dos maiores índices do estado (IDEB, 2007).

Ao problematizarmos, junto às professores de três turmas de alfabetização e pósalfabetização da escola, as dificuldades de acesso a textos escritos considerados como "adequados para a alfabetização de jovens e adultos", expressamos o nosso interesse em compreender como os enunciados dos estudantes poderiam contribuir para o ensino da língua materna.

Entendemos por enunciados a instância ativa que rege a comunicação verbal entre sujeitos falantes. Bakhtin (2000) explica melhor o significado desta noção ao nos dizer que a fala só existe, na realidade, na forma concreta dos enunciados de um sujeito. Os enunciados 


\section{$\begin{array}{llllllll}R & \mathbf{E} & \boldsymbol{V} & \mathrm{I} & \mathbf{S} & \mathbf{T} & \mathbf{A} & \text { N. } 24-2012.2-\text { MARCIA S. DE ALVARENGA }\end{array}$ \\ MARCELA P.. GARCIA}

se constituem, pois, em unidades reais da comunicação. Assim, a enunciação é formada pelo encadeamento dessas unidades que correspondem aos elos na cadeia da comunicação verbal.

Essa tese bakhtiniana se aproxima da perspectiva da teoria da ação dialógica de Paulo Freire (1987, p. 166) na relação educador-educando como sujeitos que se encontram para a pronúncia do mundo. Diálogo, no sentido freireano, não significa, apenas, fazer perguntas e ouvir respostas. Mas sim, o diálogo dialetizado pela relação "eu-tu", provocador do encontro de intencionalidades entre sujeitos que buscam, a partir da sua relação com a realidade, as razões da sua procura, das suas indagações e da sua rebeldia com o que lhes acenam sobre o já conhecido.

A partir dos autores com os quais dialogamos neste trabalho, tínhamos como hipótese a perspectiva de que jovens e adultos - como sujeitos do diálogo na corrente da comunicação verbal - produzem sentidos sobre a função social da linguagem em diferentes contextos. Por outro lado, perguntávamos como as professoras iriam dispor deste acervo enunciativo nas atividades prático-pedagógicas. Dessas inquietações, uma questão se impunha para o desafio da pesquisa: fariam sentidos para elas próprias os textos produzidos pelos seus alunos em contexto social escolar?

Os enunciados, enquanto textos, nascem do pensamento humano e são expressão das relações dialéticas e dialógicas do ser no mundo. É por isso que os textos nunca podem ser traduzidos até o fim, pois não existe um texto dos textos, potencial e único. Decorre daí a idéia de o sentido ser potencialmente infinito. $\mathrm{O}$ trabalho docente envolvendo práticas textuais orais e escritas com jovens e adultos intui sobre a necessidade de que textos produzidos por professores e estudantes não encerram em si um sentido único, cuja gestão tem na sala de aula uma de suas possibilidades do querer-dizer destes sujeitos.

Para nos ajudar a buscar responder a esta questão, recorremos a Bakhtin (2000, p. 386) ao concordarmos que sentido é aquilo que é resposta a uma indagação. Aquilo que não responde a alguma questão carece de sentido. Em suas palavras:

O sentido é potencialmente infinito, mas só se atualiza no contato com outro sentido (o sentido do outro) (...). O sentido não se atualiza sozinho, procede de dois sentidos que se encontram e entram em contato. Não há um "sentido em si". (...). Na vida histórica, essa cadeia cresce infinitamente; é por essa razão que cada um dos seus elos se renova sempre; a bem dizer, renasce outra vez. 


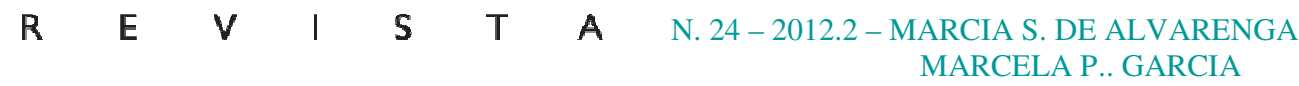

O trabalho que desenvolvemos se insere em uma corrente dialógica em que participaram "várias consciências" (pesquisadoras, professoras e estudantes da EJA), cujo movimento de ver e compreender estas consciências implicou em "ver e compreender outra consciência: a consciência do outro e seu universo, isto é, outro sujeito (um tu). (...). A compreensão sempre é, em certa medida, dialógica” (BAKHTIN, 2000, p. 338). Nestes termos, explica Bakhtin, criamos e compartilhamos relações dialógicas de sentido, cujos efeitos foram produzidos em determinadas situações do presente relato de pesquisa, mas que nelas não se esgotaram.

\section{A perspectiva teórico-metodológica da pesquisa}

Nas atividades de pesquisa desenvolvidas no período de 2010-2011 buscamos complexificar/superar a lógica que restringe as produções textuais como mera relação codificação/decodificação de signos. Com Freire (1989, p. 12) aprendemos que "a leitura de mundo precede a leitura da palavra (...). Linguagem e realidade se prendem dinamicamente. A compreensão do texto a ser alcançada por sua leitura crítica implica a percepção das relações entre o texto e o contexto".

Deste modo podemos compreender que o jovem e adulto da EJA, inseridos em diversos contextos de sociabilidades como o da família, do trabalho, da igreja, do lazer etc, produzem e atribuem sentidos aos textos que circulam em sala de aula enquanto comunidade verbal.

Se em linguagem bakhtiniana, a compreensão envolve duas consciências, dois sujeitos, vimos a possibilidade de sentidos produzidos pelas professoras dialogarem com os sentidos dos textos dos estudantes, animando o trabalho com a língua materna como móvel para o trabalho com diversos gêneros textuais. Nessa perspectiva, nos perguntamos: seria possível para as professoras das turmas da EJA, com as quais pesquisamos, buscarem caminhos teórico-metodológicos para práticas pedagógicas de ensino da língua com jovens e adultos?

A rigor, o que fundamentou as práticas de ensino de textos escritos com jovens e adultos participantes da pesquisa foi a compreensão de que suas histórias de vida narradas oralmente e/ou escritas, os diálogos produzidos em sala de aula produzem sentidos e, portanto, poderiam ser tomados como textos para o diálogo com outros textos. 
Os textos de sentidos dos jovens e adultos podem ser dialogados com as contribuições de Mikhail Bakthin e Paulo Freire. Estes autores nos legaram de maneira original e criativa, o conceito de ideologia, tendo a linguagem, como ação político-cultural, campo crítico e epistemológico que tece e é tecida por este conceito.

Se Bakhtin toma como seu intenso propósito o de demonstrar que as abordagens filosófico-linguísticas dominantes praticam um reducionismo epistemológico sobre a linguagem, aprisionando-a a um sistema abstrato e monológico, Paulo Freire, por sua vez, critica que a colonização cultural da palavra retira dela o seu marco valorativo e ideológico (idem, p. 180).

Pelas lentes de Bakhtin, a lingüística formal, ao tratar a palavra viva como se fosse algo acabado e isolado das situações e experiências sociais humanas, nada mais faz que cortar todos os fios que ligam a palavra ao contexto histórico de sua produção e, portanto, de suas múltiplas significações construídas pelos sujeitos encarnados.

Para a consciência dos indivíduos que fazem parte de uma mesma comunidade lingüística, as palavras jamais são ou se apresentam como signos contidos em formas normativas. Na realidade, comenta Bakhtin (1992, p. 95),

\footnotetext{
Não são palavras que pronunciamos ou escutamos, mas verdades ou mentiras, coisas boas ou más, importantes ou triviais, agradáveis ou desagradáveis, etc. A palavra está sempre carregada de um conteúdo ou de um sentido ideológico ou vivencial.
}

Para ele, a linguagem é um palco de lutas ideológicas que, marcadas por um tempo histórico e em um espaço social determinados, disputam a hegemonia da determinação do seu conteúdo e do seu sentido em uma sociedade.

Assim, será através dos diálogos vívidos, vividos ou imaginados que os sentidos refletem e se confrontam no e durante o percurso das amplas temporalidades contextuais. Nestes diálogos, não apenas estão presentes as vozes das pessoas que imediatamente deles participam, mas as vozes distantes que transitam no presente da interação verbal, dando-lhes e/ou confrontando-lhes sentidos.

Na leitura de Freire, o ensino da língua materna, como a alfabetização de jovens, é concebido como "um ato político e um ato de conhecimento, por isso mesmo, como um ato criador" (1989, p. 19), daí sua crítica ao ensino mecanizado que reduz o educando à condição de objeto e não de sujeito do processo educativo. A compreensão crítica do ato de ler é dotada de um movimento dinâmico em que a leitura do mundo precede a leitura da palavra: 
Este movimento do mundo da palavra e da palavra ao mundo está presente. Movimento em que a palavra dita flui do mundo mesmo através da leitura que dele fazemos. De alguma maneira, porém, podemos ir mais longe e dizer que a leitura da palavra não é apenas precedida pela leitura do mundo, mas por uma certa forma de 'escrevê-lo' ou de 'reescrevê-lo', quer dizer, de transformá-lo através de nossa prática consciente (FREIRE, 1989, p. 20).

Assim referenciadas, as relações polifônicas e dialógicas de sentidos dos enunciados/textos dos estudantes da EJA, às quais a presente pesquisa procurou manter-se atenta, sugerem a emergência de sentidos esperados e inesperados.

Em termos teórico-epistemológicos de pesquisa, com Bakhtin e Freire depreendemos que o paradigma positivista posiciona o sujeito pesquisador/a diante do seu objeto para falar sobre ele, dispensando a sua voz, pois não o reconhece nele a sua própria humanidade.

Para Bakhtin as ciências naturais produzem o conhecimento sobre a realidade de "forma monológica", significando que o pesquisador contempla o objeto, pronuncia-se sobre ele, sem com ele dialogar, pois não vê nele sua consciência refletida e refratada. Esta forma monológica só admite a existência de um único sujeito - o pesquisador - aquele que pratica o ato de conhecimento sobre o objeto. Portanto, somente o pesquisador é sujeito, negando ao outro exercer papel recíproco na produção do conhecimento, mas apenas existir enquanto coisa muda.

Por sua vez Freire (1987, p. 66) enfatiza a possibilidade que têm os seres humanos de atuar sobre a realidade objetiva e de saber que "atuam por meio de sua linguagem criadora, a pluralidade de respostas a um desafio singular, testemunham a criticidade que há nas relações entre eles e o mundo".

Nas teses de Bakhtin e Freire, as palavras, habitadas que são pelas vozes dos outros, são portadoras e partejadoras de visões de mundo no qual a língua escrita penetra a consciência e a consciência penetra a língua escrita.

\section{Diálogos com textos de jovens e adultos: produzindo sentidos para e no trabalho docente}

Durante o período de realização da pesquisa, produzimos um conjunto de registros documentais orais, escritos e em vídeo a partir das oficinas ${ }^{6}$ de produção textual junto aos

\footnotetext{
${ }^{6}$ Os temas das oficinas de produção de textos eram discutidos e selecionados em nossos encontros quinzenais com as três professoras, orientadora pedagógica e duas bolsistas de Iniciação à Docência vinculadas ao projeto, sendo uma do curso de Letras e a outra do curso de Pedagogia, ambas da FFP/UERJ. As oficinas eram
} 
jovens e adultos, das quais apresentamos alguns dos seus resultados. Mantivemos a orientação teórico-epistemológica de que o ensino da língua, em sua forma escrita, não pode ser dissociado de sua forma enunciativa na comunicação verbal viva.

Com efeito, sabemos que a linguagem oral constitui um gênero de discurso mais presente na nossa vida cotidiana e em uma comunidade dialógica. Em um contexto escolar, jovens e adultos participam desta comunidade, são locutores de um intuito discursivo de um querer-dizer. Este intuito, em diferentes situações discursivas espontâneas ou estimuladas, possui um caráter subjetivo que em combinação com o objetivo do diálogo da comunidade produz sentido, pois compreendido a partir do contexto concreto que o gerou.

Dentre os textos produzidos pelos estudantes, trazemos quatro que foram frutos da mediação das professoras em atividades entremeadas entre linguagem oral e linguagem escrita em aula. Tendo como tema "Histórias de Vida", nos excertos a seguir, os primeiros textos são transcrições de vozes dos estudantes e os dois últimos são textos escritos (para os textos escritos foram mantidas a escrita original, sem revisão ortográfica, e a disposição gráfica):

\section{Minha História}

A minha vida de criança pobre me a lembro que a minha mãezinha querida eu, ainda pequena, minha mãe pegava os meus vestidinhos velhinhos. Aproveitava a blusa da saia e a saia colocava na blusa e não tinha máquina: costurava à mão (...).

A história ainda não acabou. A história ainda é longa. Hoje eu só a mulher mais feliz na face da terra, sem luta não á vitória (Estudante do sexo feminino, 44 anos de idade, Grupo I - Alfabetização).

Eu quando era criança era muito alegre, apesar de me chamarem de gordinha, mais eu não me incomodava. Assim mesmo eu era muito feliz. Depois que a idade vai chegando nós vamos aprendendo ter responsabilidade com a vida, mais alegria continua. Aos meus 17/20/30/40/50 anos até 67 foi com muitas lutas com os meus cabelos brancos, com as dores daqui, daqui, dali não podemos perder a esperança de viver com muita alegria (Estudante do sexo feminino, 72 anos de idade, Grupo I - Alfabetização).

Nasci em Rio Bonito, num bairro muito distante do centro da cidade, era roça mesmo. Quando eu era criança fui à escola somente uma vez (Estudante do sexo masculino, 48 anos de idade, turma b, Grupo II $-2^{\mathrm{a}}$ e $3^{\mathrm{a}}$ série do Ensino Fundamental).

Quando eu era um criança

Eu tinha que trabalhar ao invez de estudar

desenvolvidas tanto por nós professores quanto pelas bolsistas em um trabalho em que articulamos formação continuada e formação inicial de professoras da EJA. 
Eu tinha que trabalhar todo os dias

E quando o padeiro passava dizendo olha o padeiro

Conpra o pão quem tem dinheiro eu ficava muito triste.

A escola eu não podia ir poque o meu pai não deixava.

Ele dizia escola não dar comida a ninguém,

Você trabalha se quiser comer (Estudante do sexo masculino, 53 anos de idade, Grupo I Alfabetização).

Augums anos atrás eu morava no

Interior costumava colocar minhas filhas

para dormir, e eu colocava a esteira do

lado de fora e ficava centada pensando na

vida, olhando para o céu, vendo as estrelas

brilhar, e vi uma estrela cadente e fiz

três pedidos... (Estudante do GII, turma a, do sexo feminino, 52 anos de idade

$-3^{\mathrm{a}}$ série do Ensino Fundamental).

Ao narrarem sua infância e vida adulta roubadas pela negação de direitos fundamentais, os estudantes buscam escrever, não só palavras que fazem parte do seu cotidiano para descrever suas lutas, suas histórias, mas, o seu querer-dizer através de um gênero do discurso, o discurso oral, ao qual buscam se ajustar independentemente de dominar a gramática e estrutura do texto escrito.

É interessante observarmos nos textos dos estudantes uma linguagem estético-poética pela qual reinventam, através de palavras, a própria vida. Ao assumir o papel de autor/a jovens e adultos, buscam reencantar a língua materna, sem as amarras dos textos escolarizados que não respondem às perguntas relacionadas à vida e às expectativas de jovens e adultos. Portanto, esvaziadas de sentidos.

Em nossos círculos de discussões e estudos quinzenais, as professoras das turmas de pós-alfabetização, respectivamente turma a e turma b, reconheceram que

É importante valorizar o aluno da EJA, suas histórias de vida, suas lutas. Hoje temos mais condições de conhecer este aluno e fazer um trabalho a partir dessas suas histórias. Mas, também é importante que eles saiam da escola sabendo ler e escrever (...). Escrever um texto com correção, pois é o que vão exigir lá fora.

A dificuldade de ter acesso a material próprio para o adulto faz, muitas vezes, que a gente utilize os livros que tem na escola. Em geral livros voltados para crianças. A gente faz adaptações dos exercícios. Mas, tenho trabalhado com muitas situações que eles trazem da vida deles, das suas histórias, das situações de trabalho. Fazemos poesias, acrósticos. Para os adultos principalmente, eles querem copiar do quadro, pois tem essa ideia de escola (...). Por isso que a gente tem que equilibrar entre o conteúdo e a sua bagagem de vida. 
Estas abordagens das professoras sobre a questão de tentar "equilibrar" o conteúdo formal do currículo escolar e os saberes e práticas dos estudantes se mostraram bastante relevante em nossas reflexões. A escola, na visão dos estudantes, é ideologizada, ou seja, historicamente se consolidou a ideia de que é através da escola que ascendemos socialmente, sendo a única via para a cidadania.

No entanto, e a despeito desta ideologia, entendemos que não podemos impor aos estudantes, de forma autoritária, uma visão de escola diferente desta que eles imaginam, mas de superar esta visão ingênua pela elaboração da crítica às limitações desta instituição na sociedade capitalista . Nesse sentido, o bom-senso é a forma como as professoras tentam orientar as práticas por elas narradas. Freire (idem, 2011, p. 64) nos chama atenção para o exercício do bom-senso nas práticas educativas dos professores:

\begin{abstract}
A responsabilidade do professor, às vezes não nos damos conta, é sempre grande. A natureza mesma de sua prática, eminentemente formadora, sublinha a maneira como a realiza. Sua presença na sala é de tal maneira exemplar que nenhum professor ou professora escapa ao juízo que dele ou dela fazem os alunos. E o pior talvez dos juízos é o que se expressa na "falta" de juízo. O pior juízo é o que considera o professor uma ausência na sala.
\end{abstract}

Em relação aos sentidos atribuídos pelos professores participantes, relembramos, também, a importância dada por Nóvoa (1995, p. 10) ao "enfatizar que esta profissão precisa de se dizer e de se contar: é uma maneira de compreendê-la em toda a sua complexidade humana e científica".

Em nossos círculos de estudos na escola, dialogamos sobre possíveis motivações que marcaram as trajetórias e sentidos profissionais que motivaram a criação de vínculos e processos identitários como professores de jovens e adultos. Identidade, não como algo fixo ou um dado adquirido, mas, como explicita Nóvoa (1995, p. 16), como processo, espaço de construção de maneiras de ser e estar na profissão".

Ser professor de EJA é participar de um campo não definido a priori e que produz sentidos que se atualizam na escola, a partir do encontro com o outro. Para as professoras,

Pensar no sujeito da EJA é pensar numa parcela da população brasileira que sofre discriminação e exploração de todo tipo por parte de um pequeno grupo dominante, eles lutam contra o sistema e arranca o direito à Educação Pública e gratuita. A história desses sujeitos é contada a partir das conquistas alcançadas através de lutas incansáveis pelo direito ao acesso a Educação. (Professora alfabetizadora - Grupo I) 
Diante de tantas necessidades, nossas e deles, é com eles e com os colegas da escola que nos inventamos como professores de EJA. (Professora do Grupo II, turma a).

São tantas as dificuldades pelos quais os estudantes nos revelam e que passam na vida, que penso que nossa formação volta a acontecer de modo diferente. Aliás, ela acontece todos os dias, pois cada dia exige de nós uma resposta diferente de ser professor de jovens e adultos. (Professora do Grupo II, turma b).

Nesse aspecto, é interessante voltarmos a Freire (1992) quando ele nos afirma que um dos erros mais frequentes nos trabalhos com grupos populares, advém da tendência de querermos levar para os sujeitos aos quais nos dirigimos a nossa "verdade" técnica e científica, sem refletir sobre os condicionantes sociais, históricos e culturais que produziram a realidade na qual vivem esses sujeitos.

Outro erro freqüente, explica Freire, é o de subestimarmos o poder e a capacidade que as classes oprimidas possuem de conhecer e problematizar a sua própria realidade, sem ter que esperar que algum "iluminado" venha a fazer isso por elas e para elas.

Dessa presunção elitista e epistemológica, acrescenta o autor, surge a atitude preferencial dos técnicos ou intelectuais em transformarmos as classes oprimidas em objeto de conhecimento ou o receptor passivo das doações ou idéias às quais lhes introjetam.

Os textos de jovens e adultos parecem ressonar junto a esta reflexão freireana, pois conhecem a língua materna e engendram esforços para ajustar seus enunciados à forma da língua escrita. Em outra atividade realizada no Grupo II, turma A, o poema "Retrato Natural", de Cecília Meireles, foi lido para a turma pela professora e bolsista de iniciação à docência, sendo, em seguida proposto, aos estudantes que reescrevessem o poema a partir de um olhar sobre si mesmo:

\section{$\mathrm{O}$ meu retrato}

O meu rosto hoje é notável,

Mas foi um pouco melhor.

Os meus cabelos têm uns grisalhos

E perderam o brilho.

A minha face é leve, vejo um pouco cansada.

Os meus olhos pretos, perfeitos, obsevadores, transmitem paz. (Estudante do sexo feminino, 46 anos de idade, GII $-3^{\mathrm{a}}$ e $4^{\mathrm{a}}$ série do Ensino Fundamental). 


\section{N. 24 - 2012.2 - MARCIA S. DE ALVARENGA MARCELA P.. GARCIA}

O meu retrato

Hoje sinto no rosto as margas

Do meu cansaço, nas minhas

Mãos ainda que cansada de tanto

Trabalhar, mais assim mesmo

Continuam a serem ages!

(Estudante do sexo feminino, 56 anos de idade, GII $-3^{\mathrm{a}}$ e $4^{\mathrm{a}}$ série ensino fundamental).

A linguagem poética nos escritos dos estudantes organizam as suas falas, moldando-a às formas gramaticais. Essa análise se ancora na ideia de que

A língua materna - a composição de seu léxico e sua estrutura -, não a aprendemos nos dicionários e nas gramáticas, nós a adquirimos mediante enunciados concretos que ouvimos e reproduzimos durante a comunicação verbal viva que se efetua com os indivíduos que nos rodeiam (BAKHTIN, 2000, p. 301).

Os textos escritos de jovens e adultos, sejam através de um gênero discursivo cotidiano biográfico, sejam através de gênero literário (Minha História, O meu retrato, por exemplo) enunciam os lugares sociais de sentidos, vale dizer, os contextos vividos, a saga heróica de homens e mulheres simples. Estes textos expressam a poesia do vivencial como sugere Martins (2005). São fragmentos com os quais tentam construir o mosaico de suas vidas e imaginar possibilidades de existência digna. Por isto mesmo, entendemos que quando as professoras discutiam sobre o ensino da língua materna, cotejando os textos dos estudantes, acabavam por produzir sentidos aos textos, mantendo viva a corrente dialógica de uma comunidade discursiva, trazendo para a sala de aula a poesia do vivencial em que elas, também, eram autoras.

Ao balizarmos o trabalho docente nesta perspectiva, nos aproximamos, uma vez mais de Paulo Freire ao defender que os textos escritos por jovens e adultos é fruto de um quefazer que os envolve em suas relações com o mundo e com os outros. Vale dizer, os saberes das classes populares são saberes construídos de sua compreensão sobre o mundo, da sua experiência de vida, de trabalho, de afetos, de sua experiência ética e estética, da sua relação com os outros e, portanto, são saberes do cotidiano e da forma como se relacionam com o mundo.

Esse processo tem no diálogo um princípio fundamental, pois o educador, ao dialogar com o educando, o faz sobre situações concretas e enunciados concretos, promovendo 


\section{$\begin{array}{llllllll}\mathbf{R} & \mathbf{E} & \boldsymbol{V} & \mathbf{I} & \mathbf{S} & \mathbf{T} & \mathbf{A} & \text { N. } 24-2012.2-\text { MARCIA S. DE ALVARENGA }\end{array}$ \\ MARCELA P.. GARCIA}

mediações sobre o contexto e os meios com e pelos quais o educando se reconhece e, com os quais, possa se alfabetizar e dar continuidade ao processo de alfabetização.

Nesse aspecto, esclarece, também, Bakhtin, a língua escrita é marcada, não somente pelos gêneros secundários (literários, científicos, filosóficos, entre outros), mas, também, pelos gêneros primários (linguagem familiar, do trabalho, do cotidiano, entre outros).

Ainda sobre a análise dos enunciados escritos por jovens e adultos, Geraldi (1999) nos chama atenção sobre o fato de que o ensino da língua materna com ênfase na gramática tem sido compreendido, tradicionalmente, como o meio de correção da expressão lingüística dos estudantes, descartando as possibilidades que a linguagem cotidiana pode oferecer para ampliar a sua participação na comunidade dialógica.

Procede deste pensamento a ideia de que as relações dialógicas são sempre relações de sentido, sejam elas produzidas entre enunciados de um diálogo real imediato, sejam elas produzidas pelas concepções ou pontos de vista criados por outras pessoas ou grupos sociais em tempos e espaços distintos.

A rigor, nossa fala e enunciados estão repletos de palavras dos outros, caracterizadas em graus variados pela alteridade ou pela assimilação, pelo emprego consciente ou não das palavras do outro. Ao dialogarmos com os textos de jovens e adultos, podemos analisar que estes trazem para o gênero discursivo palavras de outros e introduz o seu próprio tom valorativo, a sua própria expressividade, atribuem novas expressividades e novos tons valorativos juntando-se à ciranda polifônica que ressona em seus enunciados.

\section{(In) conclusões como pretexto para outros diálogos}

O diálogo solidário e polifônico com professores de jovens e adultos que atuam no sistema público de ensino em um dos maiores municípios do leste metropolitano do estado do Rio de Janeiro teve como objeto de estudo os sentidos atribuídos aos enunciados dos estudantes das turmas dos anos iniciais do ensino fundamental.

$\mathrm{Na}$ pesquisa realizada, pareceu-nos possível e rico dialogarmos com Paulo Freire e Mikhail Bakhtin, sobre o que de original e criativo estes autores nos sugerem a respeito do ensino da linguagem materna. Com efeito, este diálogo tem nos permitido ampliar as possibilidades teórico-metodológicas da pesquisa junto aos professores, especialmente, nas reflexões e análises sobre o trabalho voltado ao ensino da língua materna. 
Procurando enfatizar os enunciados orais e escritos dos estudantes de jovens e adultos, compreendemos ser fundamental atribuir sentidos aos seus enunciados como gêneros discursivos, entendidos como objetos de diálogos, portanto de sentidos, para as atividades de ensino da língua materna. A valorização dos enunciados dos jovens e adultos, enquanto sujeitos de uma comunidade dialógica, nos permite compreendê-los como textos, cuja forma escrita nos informa sobre o conhecimento produzido, suas visões de mundo e (re) criação de seus cotidianos de lutas, trabalho e sonhos.

A pesquisa tem contribuído para o aprofundamento compreensivo sobre o papel da linguagem na mediação entre o sujeito-mundo, como defende Paulo Freire, buscando entender: aquilo sobre o que falamos emerge de contextos, ao contrário do que, durante muito tempo, foi apregoado por determinadas teorias linguísticas ao separarem a palavra do mundo que a criou, como acentua Bakhtin.

Isso nos remete aos pressupostos bakhtinianos que tão bem despertaram essa dimensão dialógica sobre enunciados verbais enquanto signos ideológicos. Para este autor, a palavra não pode ser tomada fora da enunciação, pois é esta que lhe dá vida inserindo-a no processo ininterrupto da comunicação e garantindo a sua polifonia.

Quando nós, professores de jovens e adultos, realizamos o trabalho de ensino da língua materna, quando alfabetizamos, não podemos desconsiderar que os enunciados dos jovens e adultos constituem gêneros discursivos que transitam entre o primário (a linguagem do cotidiano) e o secundário (linguagem complexa) e que se hibridizam em uma comunidade dialógica na qual o ensinar e o aprender não mantém rígida relação assimétrica.

Como diálogo pressupõe trocas de enunciados, a escuta destes enunciados dão vigor à pronúncia de quem os diz. Nesse sentido, confirmamos com Paulo Freire a necessidade sobre o aprendizado do "saber escutar", pois,

[...] somente quem escuta paciente e criticamente outro, fala com ele, mesmo que, em certas condições, precise de falar a ele. [...] O educador que escuta aprende a difícil lição de transformar o seu discurso, às vezes necessário, ao aluno, em uma fala com ele (FREIRE, 1996, p. 113).

Entendemos a escuta sobre o querer-dizer como uma ponte por onde transitam os sentidos dos discursos de professores e estudantes de jovens e adultos. Por ela estes sujeitos podem se determinar a realizarem encontros dialógicos sobre objetos de sentidos, como afirma Bakhtin (1992, p. 95), a propósito da forma como reagimos às palavras que pronunciamos ou escutamos: 
A palavra está sempre carregada de um conteúdo ou de um sentido ideológico ou vivencial. É assim que compreendemos as palavras e somente reagimos àquelas que despertam em nós ressonâncias ideológicas ou concernentes à vida.

Para nós que desenvolvemos a presente pesquisa, significa que, na prática da docência com jovens e adultos, o ensino da língua materna pressupõe, inequivocamente, realizar-se com textos que despertem dialogicamente, em professores e estudantes da EJA, às ressonâncias sobre o que move os nossos sentidos sobre a vida em diferentes contextos e relações.

Ainda sobre os resultados da pesquisa, ressaltamos dois relevantes aspectos: se, por um lado a preocupação por parte das professoras com a correção linguística se manteve como objetivo principal do ensino da língua materna, por outro lado os enunciados dos estudantes foram reconhecidos como textos, objetos de sentido para o ensino da língua, em que em diálogo com outros textos, favoreceu o encontro de várias consciências, de vários textos.

\section{Referências bibliográficas:}

BAKHTIN, M. Estética da criação verbal. São Paulo: Martins Fontes, 2000. 1992. Marxismo e filosofia da linguagem (V. N. Volochinov). 6. ed. São Paulo: Hucitec,

FREIRE, P. Pedagogia da Esperança. Um reencontro com a Pedagogia do oprimido. São Paulo: Paz e Terra. 1996.

1989.

A importância do ato de ler: em três artigos que se completam. São Paulo: Cortez, Ação cultural para a liberdade. Rio de Janeiro: Paz e Terra, 1982.

Educação e Mudança. Rio de Janeiro: Paz e Terra, 1979.

GERALDI, W. J. Da sala de aula à construção externa da aula. In. ZACCUR, E. (Org.) A magia da linguagem. Rio de Janeiro DP\&A, 1999.

OLIVEIRA, M. K. Jovens e adultos como sujeitos de conhecimento e aprendizagem. In. Revista Brasileira de Educação. Caxambu, set./out./nov./dez. 1999.

MARTINS, J. S, ECKERT, C. e CAIUBY, N. (Orgs.). O imaginário e o poético em ciências sociais. Bauru, SP: Edusc, 2005. 
MARTINS, J. S. A sociabilidade do homem simples. São Paulo: Hucitec, 2000.

PEZZOLO, C. Ensino noturno realidade ou ilusão. São Paulo: Cortez, 1986.

SANTOS, M. Técnica espaço tempo. Globalização e meio técnico-científico informacional. São Paulo: Hucitec, 1994.

\title{
Teaching youth and adults using Paulo Freire and Mikhail Bakhtin's dialogical perspective
}

\begin{abstract}
The research was carried out among teachers giving literacy classes to both youth and adults. These classes made us want to better understand how students' oral and written enunciations might help to overcome dificulties in teaching their native tongue in the early stages of literacy classes. Guided by the dialogical perspectives of Paulo Freire and Bakhtin, the problem of how teachers use this collection of students' enunciations presented an epistemological challenge regarding how these teachers understand the students' texts produced in their classes. The research results highlight two relevant aspects: if, on the one hand, concern over correcting language errors is still the main objective of teaching one's mother tongue, on the other, the students' enunciations were recognized as texts and as being a meaningful part of the literacy process, thus stimulating a meeting-together of various forms of conscienceness and texts.
\end{abstract}

Key words: Teaching. Youth and adult literacy. The dialogical process.

Recebido em: 23 de dezembro de 2012.

Aprovado em: 02 de janeiro de 2013. 